\title{
A Case of Membranous Nephropathy with Primary Biliary Cirrhosis and Cyclosporine-induced Remission
}

\author{
Yusuke Sakamaki ${ }^{1}$, Matsuhiko Hayashi ${ }^{2}$, Shu Wakino ${ }^{1}$, Seiichi Fukuda ${ }^{1}$, \\ Kounosuke Konishi ${ }^{1}$, Akinori Hashiguchi ${ }^{3}$, Koichi Hayashi ${ }^{1}$ and Hiroshi Itoh ${ }^{1}$
}

\begin{abstract}
We report a case of membranous nephropathy with primary biliary cirrhosis (PBC). A 76-year-old Japanese man had been treated for PBC and was referred to our department because of acute severe proteinuria (10 g/day). Renal biopsy was performed and was compatible with a diagnosis of membranous nephropathy. The patient was treated with cyclosporine A $\left(\mathrm{CsA}\right.$; Neoral $\left.{ }^{\mathbb{R}}\right)$, which was followed by normalization of liver function and partial remission of proteinuria ( $0.68 \mathrm{~g} /$ day $)$ within six months without any significant side effects. This case suggests that CsA monotherapy is effective for the treatment of both liver dysfunction and membranous nephropathy associated with PBC.
\end{abstract}

Key words: membranous nephropathy, primary biliary cirrhosis, nephrotic syndrome, cyclosporine

(Intern Med 50: 233-238, 2011)

(DOI: 10.2169/internalmedicine.50.4020)

\section{Introduction}

Membranous nephropathy is the most common cause of idiopathic nephrotic syndrome in adults and accounts for approximately $20 \%$ to $30 \%$ of adult cases. Although membranous nephropathy is often idiopathic, this form of nephropathy is known to be caused by a variety of diseases including malignant tumors, drugs and various autoimmune disorders. Although the treatment of membranous nephropathy remains to be determined, a meta-analysis of randomized controlled trials (1) investigating the effects of corticosteroid monotherapy demonstrated no beneficial effect on renal survival or the remission of proteinuria. Furthermore, in a report on the efficacy of cyclosporine A (CsA) in patients with membranous nephropathy (2), a higher incidence of relapse than that attained after steroid and other immunosuppressant therapies was found. Here, we present a case of membranous nephropathy with primary biliary cirrhosis (PBC) in which CsA monotherapy was effective for alleviating both nephropathy and PBC.

\section{Case Report}

A 70-year-old Japanese man visited the Gastroenterology Clinic at Keio University Hospital for further evaluation of a high $\gamma$-glutamyltranspeptidase $(\gamma$-GTP) value $(329 \mathrm{U} / \mathrm{L}$; normal range, 10-90 U/L) observed during a regular checkup. He was diagnosed as having PBC based on laboratory findings and radiology and ultrasonography examinations. Thereafter, he was treated with ursodeoxycholic acid (UDCA, $300 \mathrm{mg} /$ day) and bezafibrate (400 mg/day). Six years after the onset of PBC, he suddenly developed severe proteinuria (10.1 g/day, day 103) and was admitted to the Division of Nephrology at Keio University Hospital.

At the time of admission, the patient was $169.5 \mathrm{~cm}$ tall and weighed $57.5 \mathrm{~kg}$. His blood pressure was 132/78 $\mathrm{mmHg}$, and his pulse rate was 66 beats/min with a regular rhythm. A physical examination revealed normal respiratory sounds over the lungs and no cardiac murmur. Neither jaundice nor other signs suggestive of liver dysfunction, such as hepatosplenomegaly, were observed. Pretibial and pedal edema was present. He had been taking UDCA (300 mg/ day) and bezafibrate (400 mg/day) for the treatment of PBC

${ }^{1}$ Division of Endocrinology, Metabolism and Nephrology, Department of Internal Medicine, Keio University, Japan, ${ }^{2}$ Center for Apheresis and Dialysis, Keio University, Japan and ${ }^{3}$ Department of Pathology, Keio University, Japan

Received for publication May 29, 2010; Accepted for publication October 13, 2010

Correspondence to Dr. Yusuke Sakamaki, yusuke0225@dance.ocn.ne.jp 
Table 1. Laboratory Data on Admission

\begin{tabular}{|c|c|c|}
\hline & Biochemistry, Serology & Laboratory data of the patient \\
\hline \multirow[t]{26}{*}{ Serum } & Total protein & $\underline{6.2} \mathrm{~g} / \mathrm{dL}$ \\
\hline & Albumin & $1.9 \mathrm{~g} / \mathrm{dL}$ \\
\hline & Creatinine & $1.0 \mathrm{mg} / \mathrm{dL}$ \\
\hline & Aspartate aminotransferase (AST) & $\underline{45} \mathrm{U} / \mathrm{L}$ \\
\hline & Alanine aminotransferase (ALT) & $30 \mathrm{U} / \mathrm{L}$ \\
\hline & $\gamma$ glutamyltransferase $(\gamma \mathrm{GTP})$ & $266 \mathrm{U} / \mathrm{L}$ \\
\hline & Alkaline phosphatase (ALP) & $\underline{348} \mathrm{U} / \mathrm{L}$ \\
\hline & Total bilirubin & $0.4 \mathrm{mg} / \mathrm{dL}$ \\
\hline & Total cholesterol & $\underline{397} \mathrm{mg} / \mathrm{dL}$ \\
\hline & Immunoglobulin G (IgG) & $917 \mathrm{mg} / \mathrm{dL}$ \\
\hline & Immunoglobulin A (IgA) & $\underline{531} \mathrm{mg} / \mathrm{dL}$ \\
\hline & Immunoglobulin M (IgM) & $\underline{1086 \mathrm{mg} / \mathrm{dL}}$ \\
\hline & Complement 3 (C3) & $173 \mathrm{mg} / \mathrm{mL}$ \\
\hline & Complement 4 (C4) & $23 \mathrm{mg} / \mathrm{mL}$ \\
\hline & $50 \%$ hemolytic complement (CH50) & $49.8 \mathrm{U} / \mathrm{L}$ \\
\hline & Anti-nuclear antibody (ANA) & Negative \\
\hline & Anti-streptolysin O (ASO) & $<51 \mathrm{U} / \mathrm{L}$ \\
\hline & Rheumatoid factor (RF) & $<10 \mathrm{U} / \mathrm{mL}$ \\
\hline & Anti-double strand DNA antibody & $<1 \mathrm{U} / \mathrm{mL}$ \\
\hline & Anti-smooth muscle antibody & 2.2 Index \\
\hline & Anti-SSA/Ro antibody & 0.0 Index \\
\hline & Anti-SSB/La antibody & 1.9 Index \\
\hline & Erythrocyte sedimentation rate & $\underline{124} \mathrm{~mm} / \mathrm{hr}$ \\
\hline & Cryoglobulin-IgM (C-IgM) & $\underline{\text { Positive }}$ \\
\hline & Anti-mitochondrial M2 antibody & $\underline{176.0 \text { Index }}$ \\
\hline & Estimated glomerular filtration rate (eGFR) & $40.8 \mathrm{~mL} / \mathrm{min} / 1.73 \mathrm{~m}^{2}$ \\
\hline \multirow[t]{7}{*}{ Urine } & Red blood cells (RBC) & $<6-10 / \mathrm{hpf}$ \\
\hline & White blood cells (WBC) & $<2 / \mathrm{hpf}$ \\
\hline & Hyaline, granular and WBC casts, fat cell casts & All positive \\
\hline & Urinary protein excretion/24-h & $\underline{10.1 \mathrm{~g} / \mathrm{day}}$ \\
\hline & Selectivity Index & 0.09 \\
\hline & $\beta 2$ microglobulin & $3171 \mu \mathrm{g} /$ day \\
\hline & N-Acetyl- $\beta$-D-glucosaminidase & $67.1 \mathrm{U} / \mathrm{g} \mathrm{Cr}$ \\
\hline
\end{tabular}

at the time of his admission. He was treated with furosemide $(20 \mathrm{mg} /$ day $)$ because of severe edema. Serum markers for viral infection, including hepatitis $\mathrm{B}$ virus (HBV) surface antigen, hepatitis $\mathrm{C}$ virus (HCV) antibody and human immunodeficiency virus (HIV) antibody, were all negative.

The patient's laboratory data are shown in Table 1. Increased immunoglobulin (Ig) levels and cryoglobulin-IgM (C-IgM) positivity were compatible with a diagnosis of $\mathrm{PBC}$, and the reduced serum albumin level and large amount of proteinuria confirmed the diagnosis of nephrotic syndrome. Computed tomography of the abdomen and a gastric endoscopy examination showed no evidence of malignancy or any other abnormality.

A renal biopsy was performed (on day 103) three months after the onset of proteinuria. The biopsy specimen contained nine glomeruli. One glomerulus in the subcapsular region was obsolete. Another showed global capillary loop collapse. The remaining glomeruli occasionally exhibited a minimal mesangial increase and rare adhesion to Bowman's capsule. The capillary walls, however, were thin and delicate without suggestion of subepithelial deposits (Fig. 1A). The interlobular arteries contained intimal hyalinosis, and the tubulointerstitium showed minor foci of tubular atrophy and fibrosis. Using immunofluorescence, intense staining (3+) representing diffuse, fine granular deposits of IgG (Fig. 1B) and $\operatorname{IgM}$ was observed along the capillary walls. A similar but less intense deposition of IgA, C3 and fibrinogen was also seen. Electron microscopy revealed diffuse subepithelial electron-dense deposits without organized structures arranged somewhat sparsely throughout most of the regions (Fig. 1C). Subendothelial deposits were observed in an isolated focus (Fig. 1D). A widened subendothelial space containing what appeared to be deposits with a lower electron density were also seen at another site (Fig. 1D). However, mesangial cell interposition was not obvious. The visceral epithelial cells exhibited a widespread effacement of their foot processes. Based on these laboratory data and histological findings, the patient was diagnosed as having membranous nephropathy associated with PBC. 


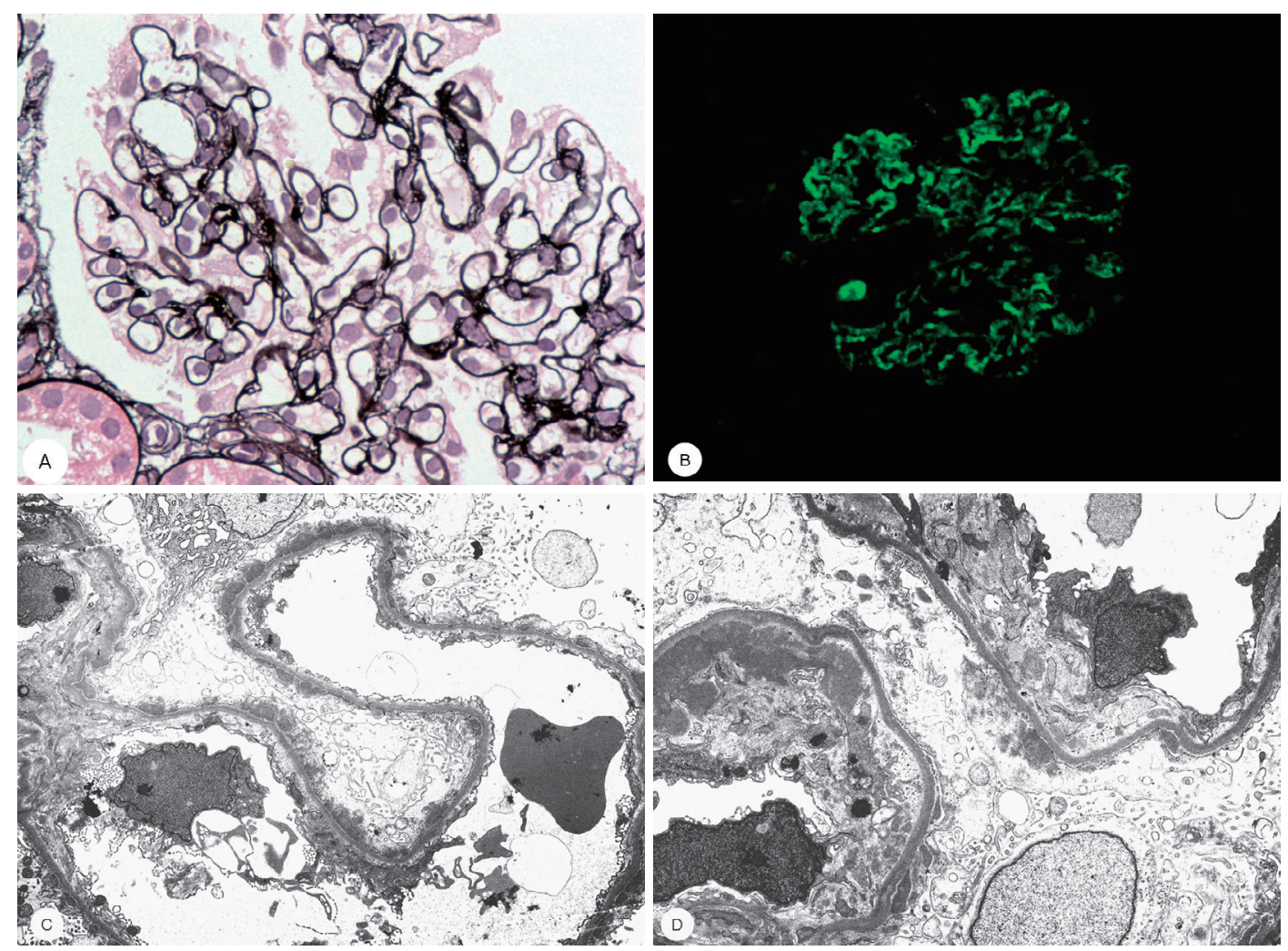

Figure 1. Renal biopsy findings. (A) Light photomicrograph showing a representative glomerulus with patent capillary lumina and normal appearing capillary wall basement membrane (periodic acid-methenamine-silver staining). (B) Immunofluorescence showing fine granular deposits of IgG along the capillary walls. (C) Electron micrograph showing subepithelial electron dense deposits. (D) Subendothelial deposits in association with a widened lamina rara interna were also observed in an isolated focus by electron microscopy.

We selected CsA (Neoral ${ }^{\mathbb{B}}$ ) monotherapy as an immunosuppressive agent because of the presence of acute severe proteinuria as well as the patient's age, the possibility of osteomalacia due to the vitamin D malabsorption, and the risk of steroid-induced osteoporosis and femur head necrosis. The administration of CsA (75-125 mg/day, started on day 154), together with UDCA ( $300 \mathrm{mg} /$ day), candesartan cilexetil $(4 \mathrm{mg} /$ day, started on day 105$)$ and bezafibrate $(400 \mathrm{mg} /$ day, day 0-491), decreased proteinuria to $2.0 \mathrm{~g} /$ day within one month and to $0.68 \mathrm{~g} /$ day within 6 months (Fig. 2). CsA was administered once daily $(3,4)$, and the dose was adjusted by monitoring the $\mathrm{C} 2$ levels (i.e., blood concentration at 2 hours after CsA administration), with a target CsA C2 level set at $600-800 \mathrm{ng} / \mathrm{mL}$; the actual $\mathrm{C} 2$ level was $775 \pm$ $278 \mathrm{ng} / \mathrm{mL}$ (mean $\pm \mathrm{SD}, \mathrm{n}=17$ ). The serum creatinine levels remained unchanged during the treatment period $(1.0 \mathrm{mg} /$ dL). The patient's liver function also improved markedly, though the anti-mitochondria antibody value remained elevated. Because of the biochemical improvement in liver function attained with CsA, bezafibrate was discontinued on day 492. The serum alkaline phosphatase level subsequently increased.

\section{Discussion}

PBC is a chronic progressive liver disease of unknown etiology characterized by immunological destruction of the small intralobular bile ducts (i.e., chronic non-suppurative destructive cholangitis) that eventually leads to cirrhosis and liver failure. This disorder is rarely associated with the development of nephrotic syndrome, particularly of membranous nephropathy (5-15). In this case report, we have shown that the CsA monotherapy effectively alleviated the nephrotic range proteinuria as well as liver dysfunction in a patient with $\mathrm{PBC}$ and membranous nephropathy. We propose that CsA monotherapy could be an alternative for conventional treatment with steroids and other immunosuppressants. Of interest, the serum alkaline phosphatase levels increased after the discontinuation of bezafibrate in the present case (Fig. 2), a finding that is consistent with a report by Itakura et al (16) demonstrating that bezafibrate significantly lowered the serum alkaline phosphatase level in patients with PBC treated with UDCA. The salutary action of bezafibrate, however, appears to be dissociated from the improvement in the nephropathy, since the withdrawal of bezafibrate had no effect on the proteinuria.

PBC is reportedly associated with the development of 


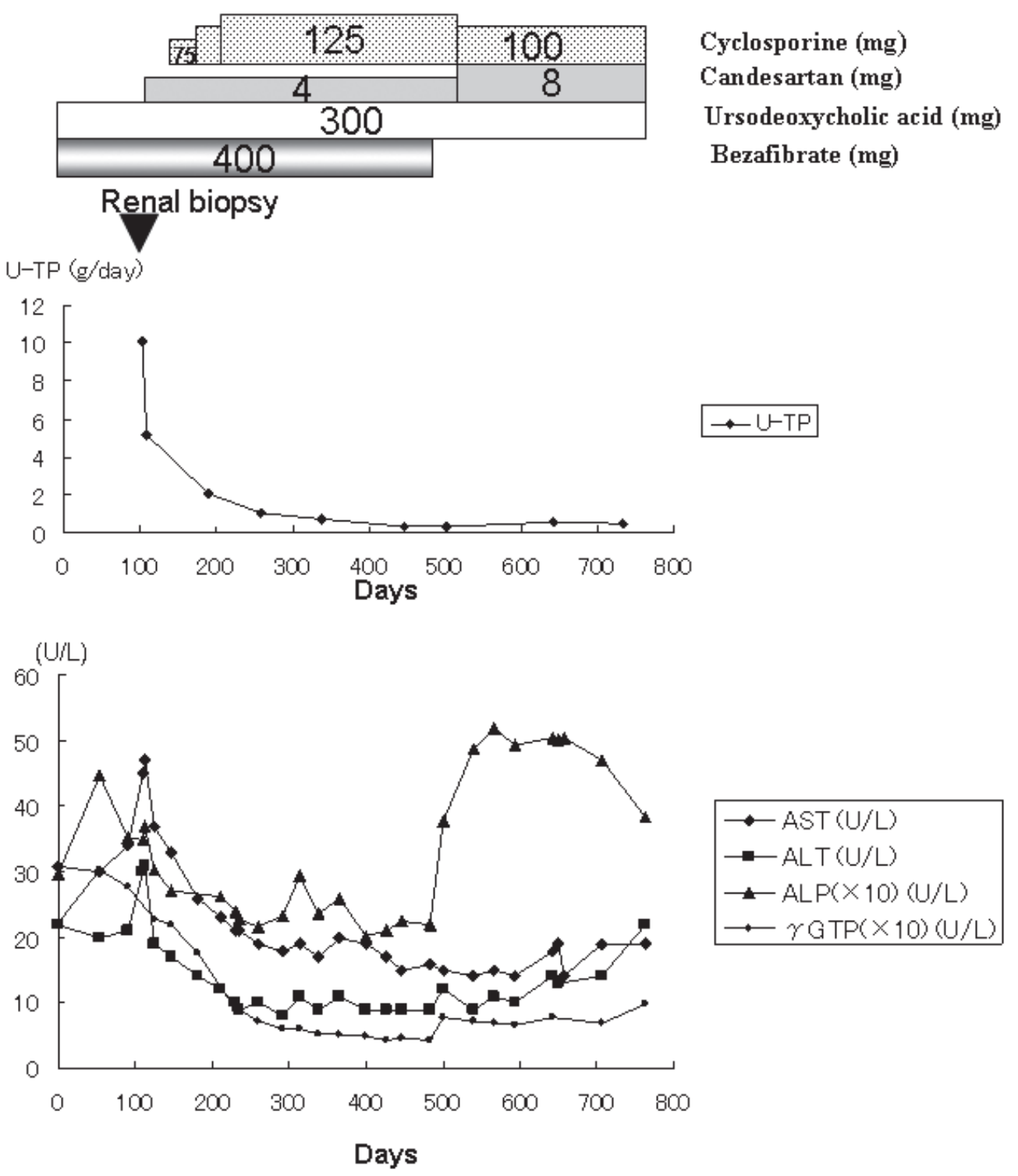

Figure 2. Temporal course of liver function and urinary protein excretion and the response to treatment. U-TP: urinary protein excretion, AST: aspartate aminotransferase, ALT: alanine aminotransferase, ALP: alkaline phosphatase, $\gamma$-GTP: $\gamma$-glutamyl-transpeptidase

membranous nephropathy (5-15). Renal immunofluorescence studies of previous cases show granular Ig deposits along the basement membrane consistent with membranous nephropathy. In the present case, the diagnosis of PBC was made based on the laboratory findings, including cholestatic liver dysfunction, an elevated serum IgM level and a positive test for antimitochondrial antibodies. Although renal biopsy failed to reveal an abnormality of the glomerular capillary walls by light microscopy, immunofluorescence showed deposition of $\operatorname{IgG}, \operatorname{IgM}, \operatorname{IgA}, \mathrm{C} 3$ and fibrinogen along the capillary walls and wide-spread subepithelial electron-dense deposits were seen by electron microscopy leading to the diagnosis of membranous nephropathy. An isolated focus of subendothelial deposits with widened lamina lara interna was observed by electron microscopy. The presence of such lesions is unusual in idiopathic membranous nephropathy, suggesting a secondary etiology. The IgG subclass of the deposition was not determined in the present case, but such a study would have been useful, since IgG4 deposition is known to be predominant in cases of idiopathic membranous nephropathy but not necessarily in secondary cases (17). Finally, cryoglobulin was detected in the serum of the present patient, enabling speculation that the cryoglobulin might have caused the glomerulopathy. Our case, however, lacks morphological features representative of cryoglobulinemic glomerulopathy (e.g., dominant subendothelial localization of electron dense deposits and the presence of organized structures within dense deposits). Moreover, Taal and Schalm (18) observed cryoglobulincontaining $\operatorname{IgM}$ in all PBC patients, but none of them had glomerulopathy. Therefore, it seems unlikely that the cryoglobulin was causally linked to the development of glomerulopathy in the present case.

Generally, corticosteroids are considered as the gold stan- 
Table 2. Characteristics of Previously Reported Cases with Primary Biliary Cirrhosis and Membranous Nephropathy

\begin{tabular}{|c|c|c|c|c|c|c|}
\hline Authors & Patients & Urinary protein & Deposition on GBM & Treatment & $\begin{array}{l}\text { Liver } \\
\text { function }\end{array}$ & $\begin{array}{l}\text { Kidney } \\
\text { outcome }\end{array}$ \\
\hline Vlassopoulos D. ${ }^{5)}$ & $61 \mathrm{~F}$ & $3.3-4.3 \mathrm{~g} /$ day & IgG, IgM & UDCA, ACE-I & Improved & ICR \\
\hline Rai GS. ${ }^{6}$ & $43 \mathrm{~F}$ & $7.2 \mathrm{~g} /$ day & IgG, IgM & n.d. & n.d. & n.d. \\
\hline Reitsma DJ. $^{7 \text { ) }}$ & $66 \mathrm{~F}$ & $<3$ g/day & IgG, IgM, C1q, C3c & n.d. & n.d. & n.d. \\
\hline Singhal PC. ${ }^{8)}$ & $69 \mathrm{~F}$ & $2.7 \mathrm{~g} /$ day & n.d. & n.d. & n.d. & Died \\
\hline Carella G. $^{9 \text { ) }}$ & $58 \mathrm{~F}$ & $0.7-1.9 \mathrm{~g} / \mathrm{L}$ & IgM, C3 & n.d. & n.d. & n.d. \\
\hline Baba A. ${ }^{10)}$ & $40 \mathrm{~F}$ & $4.7 \mathrm{~g} /$ day & $\begin{array}{c}\text { IgG, IgA, IgM, C3, } \\
\text { C4, Clq }\end{array}$ & PSL, CPM & n.d. & ICR \\
\hline Baba A. ${ }^{10)}$ & $62 \mathrm{~F}$ & $3.3 \mathrm{~g} /$ day & IgG & PSL & n.d. & $\mathrm{CR}$ \\
\hline Goto $\mathrm{T}^{11)}$ & $33 \mathrm{~F}$ & $5.3 \mathrm{~g} /$ day & $\mathrm{IgG}, \mathrm{C} 3, \mathrm{C} 1 \mathrm{q}$ & $\begin{array}{c}\text { UDCA, PSL, } \\
\text { AZT, DPM }\end{array}$ & Improved & ICR \\
\hline Hashimoto $\mathrm{Y}^{13)}$ & $59 \mathrm{M}$ & $2.4-5.6 \mathrm{~g} /$ day & n.d. & n.d. & n.d. & n.d. \\
\hline Takahashi H. ${ }^{15)}$ & $59 \mathrm{M}$ & $5.2-6.9 \mathrm{~g} /$ day & n.d. & $\begin{array}{c}\text { UDCA, DPM, } \\
\text { MZR }\end{array}$ & n.d. & HD \\
\hline
\end{tabular}

M; male, F; female, GBM; glomerular basement membrane, n.d.; not described, UDCA; ursodeoxycholic acid, ACE-I; angiotensin-converting enzyme inhibitor, PSL; predonisolone, AZT; azathioprine, CPM; cyclophosphamide, DPM; dipyridamole, MZR; mizoribine, ICR; incomplete remission, CR; complete remission, HD; Hemodialysis.

dard for the treatment of various types of autoimmune disorders. In PBC, however, steroids are not indicated as a treatment of choice (19). Alternatively, other immunosuppressive agents, including azathioprine and methotrexate, could be considered in patients who fail other treatments (20). Furthermore, CsA is reported to improve liver enzyme and serum albumin levels (21). CsA, a calcineurin inhibitor, was first introduced as an anti-rejection agent for organ transplantation that suppresses the immune response by downregulating the transcription of various cytokine-related genes. The most important cytokine involved in this effect of CsA is interleukin-2 (IL-2), which serves as the major activating factor for $\mathrm{T}$ cells in numerous immunological processes. Thus, the inhibition of IL-2 is anticipated to suppress $B$ cell activity and subsequently antibody production. In PBC, autoantibodies against 2-oxo-acid dehydrogenase complex (2-OADC) have been suggested to play a specific role in the pathogenesis of this disorder (22). Furthermore, the activation of abnormal IgM-producing $B$ cells or the inactivation of suppressor- $\mathrm{T}$ cells might contribute to the development of PBC. CsA thus is expected to be effective in ameliorating both cell-mediated and antibody-mediated autoimmune dysregulation in PBC (20).

CsA is well known to exert an antiproteinuric action in various glomerulopathies. In idiopathic membranous nephropathy, CsA therapy is effective not only for inducing remission, but for maintaining the long-term preservation of renal function (23). Regarding PBC-associated membranous nephropathy, however, no trial has been reported to date showing the beneficial effect of CsA (Table 2), although steroids alone or steroids with immunosuppressants have been reported to induce remission of nephritic syndrome; Baba et al (10) reported that prednisolone in combination with cyclophosphamide or prednisolone as a monotherapy decrease proteinuria and successfully induced complete remission. Goto et al (11) also reported that the administration of prednisolone, along with azathioprine and dipyridamole, decreased proteinuria to less than $1 \mathrm{~g} /$ day. In the present report, we demonstrated for the first time that CsA monotherapy resulted in a marked decrease in proteinuria in a patient with $\mathrm{PBC}$-associated membranous nephropathy. Our finding that the decrease in proteinuria closely parallels improvements in liver function, at least during the initial half of the treatment course (Fig. 2), suggests that this antiproteinuric action of CsA is immune-mediated. It should be noted, however, that the titer of anti-mitochondria antibody remained high during CsA therapy. This observation may be relevant to the report suggesting a non-immunologic mechanism of CsA-induced reduction in proteinuria (24).

Although the present case shows a beneficial effect of CsA, a caveat is in order in assessing the efficacy of CsA for the treatment of PBC and its associated disorders. Since CsA is also known to induce nephrotoxicity, its use requires close monitoring of the blood level. Furthermore, the longterm beneficial effects on PBC (e.g., mortality and the need for liver transplantation) have yet not been established (21). Finally, spontaneous remission is known to occur in up to $30 \%$ of patients with nephrotic syndrome arising from idiopathic membranous nephropathy, and an isolated case of PBC-associated membranous nephropathy has even been reported (7). The rapid nature of the reduction in proteinuria along with the parallel improvement in liver function after CsA therapy, however, militates this possibility. Alternatively, our patient also received candesartan cilexetil (Fig. 2), a renin-angiotensin blocking agent that exerts an antiproteinuric action in various types of nephrotic syndrome, including membranous nephropathy (25). Collectively, these findings indicate that the potential role of CsA 
in the treatment of PBC accompanied by membranous nephropathy warrants further investigation.

In conclusion, we report a case of membranous nephropathy associated with $\mathrm{PBC}$ in which CsA monotherapy induced a partial remission of nephrotic syndrome and an improvement in liver function. To the extent that the therapeutic strategy for membranous nephropathy associated with PBC remains to be established, our current observation might offer a promising tool for the treatment of this type of nephrotic syndrome.

The authors state that they have no Conflict of Interest (COI).

\section{References}

1. Hogan SL, Muller KE, Jennette JC, Falk RJ. A review of therapeutic studies of idiopathic membranous glomerulopathy. Am J Kidney Dis 25: 862-875, 1995.

2. Alexopoulos E, Papagianni A, Tsamelashvili M, Leontsini M, Memmos D. Induction and long-term treatment with cyclosporine in membranous nephropathy with the nephrotic syndrome. Nephrol Dial Transplant 21: 3127-3132, 2006.

3. Rasche FM, Keller F, Kunze G, Boesler B, Czock D. Single daily dose of cyclosporine in patients with primary glomerulonephritis and nephrotic syndrome. Clin Nephrol 67: 285-292, 2007.

4. Takeda A, Horike K, Onoda H, et al. Benefits of cyclosporine absorption profiling in nephrotic syndrome: preprandial once-daily administration of cyclosporine microemulsion improves slow absorption and can standardize the absorption profile. Nephrology (Carlton) 12: 197-204, 2007.

5. Vlassopoulos D, Divari E, Savva S, et al. Membranous glomerulonephritis associated with primary biliary cirrhosis. Nephrol Dial Transplant 13: 459-461, 1998.

6. Rai GS, Hamlyn AN, Dahl MG, Morley AR, Wilkinson R. Primary biliary cirrhosis, cutaneous capillaritis, and IgM-associated membranous glomerulonephritis. Br Med J 1: 817, 1977.

7. Reitsma DJ, Gratama S, Vroom TM. Clinical remission of membranous glomerulonephritis in primary biliary cirrhosis with cutaneous vasculitis. Br Med J (Clin Res Ed) 288: 27-28, 1984.

8. Singhal PC, Scharschmidt LA. Membranous nephropathy associated with primary biliary cirrhosis and bullous pemphigoid. Ann Allergy 55: 484-485, 1985.

9. Carella G, Marra L, Bevilacqua E. A case of membranous glomerulonephritis in the course of primary biliary cirrhosis. Am J Gastroenterol 84: 579-580, 1989.

10. Baba A, Hara S, Sato Y, Yamada K, Fujimoto S, Eto T. Three patients with nephrotic syndrome due to membranous nephropathy complicated by Sjögren's syndrome. Nippon Jinzo Gakkai Shi 47: 882-886, 2005 (in Japanese, Abstract in English).

11. Goto T, Komatsu M, Fujii T, et al. Primary biliary cirrhosis associated with membranous glomerulonephritis. Intern Med 38: 2226, 1999.

12. Tanaka T, Maezawa $A$, Matsuda $\mathrm{H}$, et al. Case of membranous glomerulonephritis associated with biliary cirrhosis and chronic thyroiditis. Nippon Naika Gakkai Zasshi 83: 995-996, 1994 (in Japanese, Abstract in English).

13. Hashimoto $Y$, Minamikata $Y$, Tamura $K$, et al. A case of nephritic syndrome with primary biliary cirrhosis. Nippon Shokakibyo Gakkai Zasshi 83: 919, 1986 (in Japanese).

14. Koshino Y, Kida H, Takasawa K, et al. Glomerular lesions in primary biliary cirrhosis. Nippon Jinzo Gakkai Shi 28: 1385-1391, 1986 (in Japanese, Abstract in English).

15. Takahashi H, Fuse I, Abe T, Yoshino N, Aizawa Y. Acquired factor $\mathrm{V}$ inhibitor complicated by Hashimoto's thyroiditis, primary biliary cirrhosis and membranous nephropathy. Blood Coagul Fibrinolysis 14: 87-93, 2003.

16. Itakura J, Izumi N, Nishimura $\mathrm{Y}$, et al. Prospective randomized crossover trial of combination therapy with bezafibrate and UDCA for primary biliary cirrhosis. Hepatol Res 29: 216-222, 2004.

17. Beck LH, Salant DJ. Membranous nephropathy: recent travels and new roads ahead. Kidney Int 77: 765-770, 2010.

18. Taal BG, Schalm SW. Cryoglobulins in primary biliary cirrhosis: prevalence and modulation by immunosuppressive therapy. Z Gastroenterol 23: 228-234, 1985.

19. Prince M, Christensen E, Gluud C. Glucocorticosteroids for primary biliary cirrhosis. Cochrane Database Syst Rev 18: CD003778, 2005.

20. Carithers RL Jr. Primary biliary cirrhosis: specific treatment. Clin Liver Dis 7: 923-939, 2003.

21. Gong Y, Christensen E, Gluud C. Cyclosporin A for primary biliary cirrhosis. Cochrane Database Syst Rev 18: CD005526, 2007.

22. Harada K, Sudo Y, Kono N, et al. In situ nucleic acid detection of PDC-E2, BCOADC-E2, OGDC-E2, PDC-E1alpha, BCOADC-E1 alpha, OGDC-E1, and the E3 binding protein (protein $\mathrm{X}$ ) in primary biliary cirrhosis. Hepatology 30: 36-45, 1999.

23. Goumenos DS. What have we learned from the use of ciclosporin A in the treatment of nephrotic patients with idiopathic membranous nephropathy? Expert Opin Pharmacother 9: 1695-1704, 2008.

24. Faul C, Donnelly M, Merscher-Gomez S, et al. The actin cytoskeleton of kidney podocytes is a direct target of the antiproteinuric effect of cyclosporine A. Nature Medicine 14: 931-938, 2008.

25. Ruggenenti $P$, Mosconi L, Vendramin G, et al. ACE inhibition improves glomerular size selectivity in patients with idiopathic membranous nephropathy and persistent nephrotic syndrome. Am J Kidney Dis 35: 381-391, 2000.

(C) 2011 The Japanese Society of Internal Medicine http://www.naika.or.jp/imindex.html 